\title{
Clear differences in cerebrospinal fluid proteome between women with chronic widespread pain and healthy women - a multivariate explorative cross-sectional study
}

\author{
This article was published in the following Dove Press journal: \\ Journal of Pain Research \\ 13 March 2017 \\ Number of times this article has been viewed
}

\section{Patrik Olausson \\ Bijar Ghafouri \\ Emmanuel Bäckryd \\ Björn Gerdle}

Pain and Rehabilitation Centre, Department of Medical and Health Sciences, Linköping University, Linköping, Sweden
Correspondence: Bijar Ghafouri Pain and Rehabilitation Medicine, PAINOMICS Research Laboratory, Division of Community Medicine, Department of Medical and Health Sciences, Linköping University, Linköping SE 58I 85, Sweden

Tel+46 I 0103238 I

Email bijar.ghafouri@liu.se
Introduction: Frequent chronic local pain can develop into chronic widespread pain (CWP). The spread of pain is correlated with pain intensity, anxiety, and depression, conditions that ultimately lead to a poor quality of life. Knowledge is incomplete about CWP's etiology, although it has been suggested that both central hyperexcitability and/or a combination with peripheral factors may be involved. Cerebrospinal fluid (CSF) could act as a mirror for the central nervous system as proteins are signal substances that activate the formation of algesics and control nociceptive processes. To this end, this study investigates the CSF protein expression in women with CWP and in female healthy controls.

Materials and methods: This study included 12 female patients with CWP diagnosed according to the American College of Rheumatology criteria with 13 healthy age- and sex-matched pain-free subjects. All subjects went through a clinical examination and answered a health questionnaire that registered sociodemographic and anthropometric data, pain characteristics, psychological status, and quality of life rating. CSF was collected by lumbar puncture from each subject. Two-dimensional gel electrophoresis in combination with mass spectrometry was used to analyze the CSF proteome. This study identifies proteins that significantly discriminate between the two groups using multivariate data analysis (MVDA) (i.e., orthogonal partial least squares discriminant analysis [OPLS-DA]).

Results: There were no clinically significant levels of psychological distress and catastrophization presented in subjects with CWP. MVDA revealed a highly significant OPLS-DA model where 48 proteins from CSF explained $91 \%\left(R^{2}\right)$ of the variation and with a prediction of $90 \%$ $\left(Q^{2}\right)$. The highest discriminating proteins were metabolic, transport, stress, and inflammatory. Conclusion: The highest discriminating proteins (11 proteins), according to the literature, are involved in apoptotic regulations, anti-inflammatory and anti-oxidative processes, the immune system, and endogenous repair. The results of this explorative study may indicate the presence of neuro-inflammation in the central nervous system of CWP patients. Future studies should be larger and control for confounders and determine which alterations are unspecific/general and which are specific changes.

Keywords: biomarkers, muscle pain, inflammation

\section{Introduction}

Pain will spread for many patients $(9 \%-25 \%)$ with chronic local/regional pain conditions, ultimately leading to chronic widespread pain (CWP). A continuum of chronic pain conditions has been proposed, ${ }^{1}$ and CWP - including fibromyalgia syndrome (FMS) - is considered the most negative end point associated with 
numerous negative implications. Spreading of pain is associated with increased pain intensity ${ }^{2,3}$ and increased prevalence of psychological symptoms such as anxiety, depression, and catastrophizing. ${ }^{3-5}$ CWP patients often report difficulties with work, increased sick leave, and poor quality of life and health. ${ }^{4,6,7}$ In the west, CWP has a relatively high prevalence $(10.6 \%){ }^{8}$

The newly proposed version 11 of the International Classification of Diseases (ICD-11) identifies CWP as the first diagnosis under the category "chronic primary pain". 9 Different alterations in the central processing of nociception (e.g., central hyperexcitability), descending facilitation, impairment of descending inhibition, and biochemical and functional alterations in networks (e.g., default mode network) of the brain are present in CWP/FMS. ${ }^{10-13}$ Neuroendocrine and autonomic nervous system alterations have also been reported. ${ }^{14,15}$ Some researchers consider FMS as mainly a central hyperexcitability pain condition. ${ }^{12,16,17}$ However, peripheral tissue alterations, ${ }^{18}$ nociceptive $\mathrm{C}$-fiber alterations (e.g., small fiber neuropathy), ${ }^{19-23}$ and nociceptive input ${ }^{24-28}$ in CWP may indicate that peripheral mechanisms maintain the central alterations.

In recent years, research has focused on identifying biomarkers related to various diseases, a development that has seemingly not yet reached its peak. Fluids such as cerebrospinal fluid (CSF), plasma, and saliva have been suggested as interesting areas. ${ }^{29-31} \mathrm{CSF}$ may mirror processes in the central nervous system (CNS) with respect to neurons and glial cells, CSF proteins, and peptides. ${ }^{30,32} \mathrm{CSF}$ is created by diffusion of interstitial fluid from the brain and passive filtration of blood through the epithelial cells. ${ }^{33}$ Intense research using CSF is ongoing in the field of neurodegenerative disorders such as Alzheimer's disease, Parkinson's disease, and multiple sclerosis. ${ }^{32}$ CSF has also attracted the interest of researchers in order to further understand the pathomechanisms of chronic pain conditions (e.g., CWP). Hence, several decades ago, CSF has been investigated with respect to beta-endorfin and substance $P$ in FMS patients. ${ }^{34,35}$ More recently, research has focused on cytokines and neurotrophic factors in CSF of different pain conditions. ${ }^{36} \mathrm{~A}$ recent review found evidence for elevated levels of nerve growth factor (NGF), brainderived neurotrophic factor, interleukin 8, and lowered levels of glial cell-derived neurotrophic factor in FMS. ${ }^{36}$ In most of these CSF studies of chronic pain conditions, only one or a few substances at a time have been analyzed. However, there is a need to take a more comprehensive approach due to the complexity of the involved nociceptive processes. ${ }^{37} \mathrm{~A}$ panel of multiple biomarkers or bio-clusters will reasonably perform better than a single or few biomarkers with respect to understanding the involved mechanisms.

Proteins act as signal substances, activate the formation of algesics, and control nociceptive processes. For the last 35 years, high-resolution two-dimensional gel electrophoresis (2-DE) has been the primary tool to impartially analyze the content of proteins in a certain tissue, i.e., the proteome. Since its inception, ${ }^{32}$-DE has gradually been refined to the technique seen today with immobilized $\mathrm{pH}$ gradients (IPG), ${ }^{33}$ high-resolution sodium dodecyl sulfate (SDS) protocols, silver staining, and, more recently, the introduction of a new complement - difference in-gel electrophoresis. ${ }^{34}$ Although modified, the basic premise of 2-DE remains the same: first-dimension separation using isoelectric focusing (IEF) and second-dimension separation by molecular weight (MW), giving a two-dimensional map of up to thousands of proteins. Data sets from the "omics" field (e.g., proteomics) are generally characterized by low subject-to-variables ratios and a large number of intercorrelated molecules/proteins, so these methods often violate central assumptions of traditional statistical methods. ${ }^{38}$ Thus, it is necessary to use modern multivariate data analysis (MVDA) methods such as advanced principal component analysis (PCA) and different types of partial least square (PLS) regressions. ${ }^{38}$ Hence, $2-D E,{ }^{39}$ mass spectrometry, and subsequent MVDA can be used to separate, quantify, and determine the important pattern of the proteins from a tissue, i.e., proteomics.

Proteomics are frequently applied in clinical research of neurodegenerative disorders, ${ }^{32}$ but proteomic CSF studies are sparse in the field of chronic pain. Such studies can be important for understanding activated nociceptive mechanisms and hopefully will be used in the long term to clinically guide diagnosis and choice of treatment. A few CSF studies using proteomics have been published - e.g., spinal nerve root injury due to lumbar disk herniation ${ }^{40}$ and neuropathic pain. ${ }^{41,42} \mathrm{~A}$ few bioinformatics-oriented studies on neuropathic pain also exist. ${ }^{43,44}$ Recently, our group in an explorative study reported that the multivariate protein pattern in CSF of patients with severe peripheral neuropathic pain clearly and significantly differed from that of healthy controls (CON). ${ }^{45}$

In this study, we hypothesized that significant differences in the proteome of CSF exist between CWP and healthy women (CON). Thus, the aim of this explorative and crosssectional study was to compare the CSF protein expression in CWP and CON using 2-DE and MVDA. 


\section{Materials and methods \\ Subjects}

Patients with CWP were recruited among former patients at the Pain and Rehabilitation Centre of the University Hospital, Linköping, Sweden. Inclusion criteria were female sex, age between 20 and 65 years, and CWP according to the American College of Rheumatology (ACR) criteria 46. Exclusion criteria were major psychiatric disorder, addiction, other significant disease (investigator's judgment), and pregnancy. Thirteen women (one excluded; "Results" section) with CWP agreed to participate in the study.

Thirteen healthy women were recruited through advertisements at Linköping University.

A structured interview was conducted to ensure the absence of any significant medical condition. The following areas were specifically assessed in the interview: earlier major trauma; back, joint, muscle, or skeletal disease; heart or vascular disease; lung or bronchial disease; psychiatric symptoms; neurological, ear, or eye disease; digestive tract disease; kidney, urinary, or genital disease; skin disease; tumor or cancer; endocrine disease; hematological disease; birth defects; and other diseases, disabilities, or allergies.

All the subjects in both groups were asked whether they had a bleeding disorder.

All potential subjects were given written and verbal information about the study, and subjects interested in participating signed a consent form that was in accordance with the Declaration of Helsinki. The study was granted ethical clearance by the Linköping University Ethics Committee (Dnr M136-06 and 2012/94-32).

\section{Clinical examination}

All subjects went through a brief clinical examination by a physician. The examination included auscultation of heart and lungs, diastolic and systolic blood pressures, routine neurological examination, and tender point examination (number of tender points is reported) according to the ACR criteria. ${ }^{46}$

As a part of the clinical examination, algometry was performed using an electronic pressure algometer (Somedic, Hörby, Sweden) as previously described. ${ }^{47}$ The diameter of the contact area was $10 \mathrm{~mm}$, and the pressure was applied perpendicularly to the skin at a speed of $30 \mathrm{kPa} / \mathrm{s}$. The subjects were instructed to mark the pressure pain threshold (PPT) by pressing a button as the sensation of "pressure" changed to "pain". Before the actual testing of PPT, the subjects were given instructions and allowed to examine the testing procedure. Algometry was performed bilaterally over the medial, middle, and lateral part of the descending part of the trapezius muscle and over the dominant (CON) or most painful side (CWP) of the tibialis anterior muscle to determine the PPTs. When the button was pressed or when the maximum pressure of $600 \mathrm{kPa}$ was reached, the application of pressure ceased. All PPT measurements were conducted twice in $\sim 5$-min intervals. The PPT values of the trapezius muscles were calculated as the mean of these two measurements of lateral, middle, and medial sites on the right and left trapezius muscle.

\section{Health questionnaire}

All subjects answered a brief health questionnaire that registered sociodemographic and anthropometric data, pain characteristics, psychological status, and quality-of-life rating.

\section{Sociodemographic and anthropometric data}

The following variables were registered: age, self-reported weight $(\mathrm{kg})$, and height $(\mathrm{m})$. Based on these two anthropometric variables, body mass index $\left(\mathrm{BMI} ; \mathrm{kg} / \mathrm{m}^{2}\right)$ was calculated.

\section{Pain characteristics}

All subjects rated pain intensity in nine anatomical regions (neck, shoulders, arms, hands, upper back, lower back, hips, knees, and feet) using a visual analog scale (VAS). The scale was $100 \mathrm{~mm}$ long with defined end points ("no pain" and "worst pain imaginable") but without marks in between (results in $\mathrm{mm}$ ).

\section{Psychological aspects}

\section{Hospital Anxiety and Depression Scale (HADS)}

The HADS, a short self-assessment questionnaire, measures the level of anxiety and depression. HADS comprises seven items in each of the depression (HADS-D) and anxiety (HADS-A) subscales. Possible subscale scores range from 0 to 21 , the lower score indicating the least depression and anxiety. A score of 7 or less indicates a non-case, a score of 8-10 indicates a doubtful case, and a score of 11 or more indicates a definite case. HADS is frequently used and has good psychometric characteristics. ${ }^{48,49}$

\section{Pain Catastrophizing Scale (PCS)}

The PCS is a 13-item self-report measure designed to assess catastrophic thoughts or feelings accompanying the experience of pain. ${ }^{50,51}$ Respondents are asked to reflect on past painful experiences and to indicate the degree to which each of the 13 thoughts or feelings are experienced when in pain. The questionnaire uses a five-point scale ranging from 0 (not at all) to 4 (all the time). Subscales 
for rumination, magnification, and helplessness plus a total score are added up. Different cutoff scores that are clinically relevant have been reported. ${ }^{52}$ In this study, the total score was used; a cutoff of 38 is generally used as indicative as catastrophizing.

\section{Quality of Life Scale (QOLS)}

The QOLS is a 16-item instrument that measures domains of quality of life: material and physical well-being, relationships with other people, social, community, and civic activities, personal development and fulfillment, recreation, and independence. In this study, the validated Swedish version was used. ${ }^{53}$ The QOLS is scored by adding up the score on each item to yield a total score ranging between 16 and 112 .

\section{Sample handling}

For both patients and controls, $10 \mathrm{~mL}$ of CSF was retrieved through lumbar puncture with a 27 GA pencil-point Whitacre needle (BD Medical, Franklin Lakes, NJ, USA) and collected into five separate tubes containing $2 \mathrm{~mL}$ each of CSF and kept on ice. All samples were centrifuged at $3000 \times g$ for $10 \mathrm{~min}$ and then controlled for blood contamination by a visual erythrocytes check. Samples with visible erythrocytes were pooled and stored separately at $-80^{\circ} \mathrm{C}$ and excluded from the study. Samples without erythrocytes were pooled and stored in aliquots at $-80^{\circ} \mathrm{C}$ pending further quality control and analysis.

\section{Quality control of samples}

Samples without obvious erythrocyte contamination were further checked for plasma contamination by determining apolipoprotein B concentration. An apolipoprotein B ratio of plasma $(\mathrm{CSF}<6000)$ was considered as non-contaminated. ${ }^{54}$ An ELISA kit (Max Discovery, Bioo Scientific Corporation, Austin, TX, USA) was used to check for plasma contamination by determining apolipoprotein B concentration.

\section{Proteomic analysis}

Samples were depleted of the high abundance proteins albumin and immunoglobulin $\mathrm{G}$ (IgG) using an Albumin and IgG Depletion SpinTrap kit (GE HealthCare, Buckinghamshire, $\mathrm{UK}$ ). Aliquots of $200 \mu \mathrm{L} \times 5$ (final volume $1 \mathrm{~mL}$ ) CSF were loaded on the SpinTrap and collected through centrifugation according to the user manual. The CSF was then desalted, lyophilized, and solubilized in sample solution as previously described. ${ }^{55}$ Protein concentration was measured before and after the depletion procedure using Bio-Rad protein assay according to Bradford. ${ }^{56}$
An amount of $300 \mu \mathrm{g}$ protein/sample was diluted in rehydration buffer (Urea $8 \mathrm{M}$, CHAPS 2\%, DTT 0.3\%, IPG buffer $0.5 \%$ ) to a final volume of $350 \mu \mathrm{L}$ and was applied on nonlinear pH gradient 3-10 IPG strips $\left(0.5^{\prime} 3^{\prime} 180 \mathrm{~mm}\right)$ (GE HealthCare). IEF was performed on IPGphore as previously described. ${ }^{55}$ The strips were then equilibrated twice (or stored in $-80^{\circ} \mathrm{C}$ until analysis) with SDS equilibration buffer. ${ }^{55}$ The second dimension, 2-DE, was performed vertically on an Ettan ${ }^{\text {TM }}$ DALTsix Electrophoresis Unit (Amersham, Pharmacia Biotech, Uppsala, Sweden) per the manufacturer's recommendations. Proteins from the IPG strip were transferred to homogenous gels homemade cast in low fluorescent cassettes $\left(1.0^{\prime} 220^{\prime} 270 \mathrm{~mm}, 14 \% \mathrm{~T}, 2.6 \% \mathrm{C}\right)$ and kept in place with $3 \mathrm{~mL}$ agarose solution $(0.05 \%)$ with a trace of bromophenol blue. The samples were run at $80 \mathrm{~V} / 10 \mathrm{~mA}^{*}$ (*per gel) for $\sim 1.5 \mathrm{~h}$, then run at up to $600 \mathrm{~V} / 40 \mathrm{~mA}^{*}$ (*per gel) for 4-5 h, i.e., until finished. SDS electrophoresis buffer was used (anodic, $25 \mathrm{mM}$ Tris, $192 \mathrm{mM}$ glycine, 0.1\% [w/v] SDS and cathodic, $50 \mathrm{mM}$ Tris, $384 \mathrm{mM}$ glycine, $0.2 \%$ [w/v] SDS, approximate $\mathrm{pH}$ 8.3). Precision Plus Protein ${ }^{\mathrm{TM}}$ All Blue (250-10 kDa) (Bio-Rad) was used as an MW standard. Gels were fixed using $500 \mathrm{~mL}$ gel of $10 \%$ methanol/7\% acetic acid in water overnight and then fluorescently stained with $500 \mathrm{~mL}$ SYPRO Ruby (Bio-Rad) and incubated overnight. Fluorescent staining was performed according to the manufacturer's staining protocol (SYPRO Ruby protein gel stain; www.probes.com). Proteins were visualized using a CCD camera VersaDoc ${ }^{\mathrm{TM}}$ Imaging system 4000 MP (Bio-Rad).

Finally, protein patterns in the digitized images were analyzed with PDQuest 8.0.1 (Bio-Rad), a computerized imaging 12-bit system designed for evaluations of 2-DE patterns. The amount of protein in a spot was assessed as background-corrected optical density, integrated over all pixels in the spot and expressed as integrated optical density (IOD). If the quantified and matched proteins were present in at least $75 \%$ of each group, they were eligible for further multivariate data analysis.

\section{In-gel digestion by trypsin}

Protein spots were excised using a homemade spot picker. The picked protein spots were digested with trypsin (Promega/ SDS Biosciences, Falkenberg, Sweden). In short, the gel pieces were washed with a mixture of acetonitrile/ammonium bicarbonate, dehydrated with acetonitrile, and incubated with $30 \mu \mathrm{L}$ of $20 \mu \mathrm{g} / \mathrm{mL}$ trypsin in $25 \mathrm{mM}$ ammonium bicarbonate overnight at $37^{\circ} \mathrm{C}$. The supernatant was transferred to a new tube, and the peptides were further extracted from the gel by incubation in $50 \%$ acetonitrile $/ 5 \%$ trifluoroacetic acid (TFA) 
for $\sim 3 \mathrm{~h}$ at room temperature while being constantly mixed. The supernatant obtained by the two steps were pooled and dried by the SpeedVac vacuum concentration system (Savant, Farmingdale, NY, USA).

\section{Protein identification by MALDI-TOF/ TOF}

The dried tryptic samples were dissolved in $3 \mu \mathrm{L}$ of $0.1 \%$ TFA. The peptides were mixed 1:1 with matrix solutions consisting of dihydroxybenzoic acid $(0.04 \mathrm{~g} / \mathrm{mL})$ in $70 \%$ acetonitrile $/ 0.3 \%$ TFA, and $1 \mu \mathrm{L}$ was applied on the target plate (stainless steel plate). Analyses of peptide masses were performed using matrix assisted laser desorption/ionization-time of flight (MALDI-TOF)/TOF MS (ultrafleXtreme ${ }^{\mathrm{TM}}$ MALDI-TOF; Bruker Daltronik GmbH, Bremen, Germany) operated in reflector mode. Spectra in the mass range of 300-3000 Da were collected, and external mass calibration with a standard peptide mixture was used. The spectra were also internally calibrated using trypsin autolysis peptides as described previously. ${ }^{57}$

\section{Protein identification by Orbitrap mass spectrometry}

The dried tryptic samples were dissolved in $6 \mu \mathrm{L}$ of $0.1 \%$ formic acid. Peptides were analyzed, and data were acquired using Linear Trap Quadropole (LTQ) Orbitrap Velos Pro hybrid mass spectrometer (Thermo Fisher Scientific, Waltham, MA, USA) in conjunction with nanoflow highperformance liquid chromatography system (EASY-Nlc II, Thermo Fisher Scientific). Peptides were separated by reverse-phase chromatography on a $20 \mathrm{~mm} \times 100 \mu \mathrm{m} \mathrm{C} 18$ pre-column followed by a $100 \mathrm{~mm} \times 75 \mu \mathrm{m}$ C18 column (particle size $5 \mu \mathrm{m}$; Nanoseparations, Nieuwkoop, the Netherlands) at a flow rate of $300 \mathrm{~nL} / \mathrm{min}$ for $45 \mathrm{~min}$. The gradient buffers were $0.1 \%$ formic acid in water (buffer $\mathrm{A}$ ) and $0.1 \%$ formic acid in acetonitrile (buffer B), and a linear gradient from $0 \%$ to $100 \%$ of buffer B was used for separation (45 min). Automated online analyses were performed with LTQ Orbitrap Velos Pro hybrid mass spectrometer with nano-electrospray source $-240^{\circ} \mathrm{C}$ capillary temperature and spray voltage of $2200 \mathrm{~V}$. MS spectra were acquired in profile mode by Fourier transform mass spectrometery at a resolution of 30000 (at m/z 400). The top 20 most intense multiply charged ions were selected with an isolation window of 2.0 and fragmented in the linear ion-trap by collision-induced dissociation with normalized collision energy of 30 . Dynamic exclusion of sequenced peptides for $60 \mathrm{~s}$ and charge state filtering disqualifying singly charged peptides were activated and predictive automatic gain control was enabled. Centroid mode was used for collision induced dissociation tandem mass spectrometry.

\section{Database searches}

Data processing of the spectra from MALDI-TOF was performed with flexAnalysis v.3.4 (Bruker Daltonik $\mathrm{GmbH}$ ). The generated peptide mass list (mass $+\mathrm{H}^{+}$) of the major peaks from MALDI-TOF analysis was submitted to a database search (NCBI or SWISS-PROT) using MS-fit search engines. Parameters were set as species (human), mass tolerance (50 ppm), maximum missed cleavages by trypsin $\leq 1$, fixed modification (carbamidomethylation), dynamic modification (oxidation of methionine), N-terminal glutamine to pyroglutamate, and $\mathrm{N}$-terminus acetylation.

Data from the Orbitrap mass spectrometer were searched with MaxQuant version 1.5 with trypsin as a digestion enzyme against a human taxonomy of the SwissProt database (release February 2016). The following parameters were used: maximum number of missed cleavages 2 ; fragment ion mass tolerance $0.5 \mathrm{Da}$; parent ion mass tolerance $6 \mathrm{ppm}$; fixed modification - carbamidomethylation of cysteine; and the variable modifications-N-terminal acetylation and methionine oxidation. Data were filtered at $1 \%$ false discovery rate. Identifications were based on a minimum of two unique peptides.

\section{Statistics}

For age, anthropometric data, blood pressures, PPTs, number of tender points, pain intensities, depressive and anxiety symptoms, catastrophizing scale, and quality-of-life data, Student's $t$-test for unpaired data was applied using IBM SPSS v.21.0; $p<0.05$ was considered significant.

MVDAs were performed using SIMCA v.13.0 (UMETRICS, Umeå, Sweden). When applying MVDA, the recommendations concerning omics data presented by Wheelock and Wheelock ${ }^{38}$ were followed. Variables were mean centered and scaled for unified variance (UV scaling). An unsupervised PCA was first used to check multivariate outliers among all the observations/proteins. ${ }^{58}$ In the second step, when investigating the multivariate correlations between the proteins and group membership, orthogonal partial least squares discriminant analysis (OPLS-DA) was applied. ${ }^{58}$ In the OPLS-DA, variables (regressors) were considered important if they had regression coefficients with a jackknifed 95\% confidence interval not including 0 , and the variable of importance (VIP) value was greater than 1 . The OPLS-DA analysis was made in two steps. First, all proteins were included, and from this analysis, proteins were selected with VIP $>1.0$ combined with the jackknifed confidence intervals in the coefficients plot 
not including 0 and used in a new regression presented in the results. Coefficients (PLS scaled and centered regression) were used to note the direction of the relationship (positive or negative). The ratio of protein alteration (i.e., the ratio between CWP and CON) was calculated using the mean values of IOD for each protein per group. The $p$ (corr) is the loading of each variable scaled as a correlation coefficient and thus standardizing the range between -1 and +1 . The $p$ (corr) is stable during iterative variable selection and comparable between models. An absolute $p$ (corr) $>0.4-0.5$ is generally considered significant. ${ }^{38} R^{2}$ describes the goodness of fit - the fraction of sum of squares of all the variables explained by a principal component. $Q^{2}$ describes the goodness of prediction - the fraction of the total variation of the variables that can be predicted by a principal component using cross-validation methods. $R^{2}$ should not be considerably higher than $Q^{2}$. A difference $>0.2-0.3$ implies overfitting, meaning that the robustness of the model is poor. ${ }^{58}$ To validate the model, obtained cross-validated analysis of variance (CV-ANOVA) was used. The multivariate regressions were considered of significant importance if the CV-ANOVA had $p<0.05$.

\section{Results}

\section{Background data}

No significant age or height differences were found between the two groups (Table 1). CWP $(n=12)$ had significantly higher weight and BMI than CON $(n=13)$ (Table 1). Small but significant differences were found in blood pressures. As expected, prominent differences were found in pain intensities and number of tender points (Table 1).

Although significant group differences existed according to the anxiety and depression scales of HADS, none of these values were above the clinical cutoff (i.e., $>10$ ), indicating anxiety or depression. A significant difference also existed for PCS, but on the group level, CWP had a level well below the cutoff used for catastrophizing (i.e., >38). QOLS showed a significant group difference with a worse situation for CWP.

\section{Proteome profile}

A CSF sample of one patient exceeded the apolipoprotein $\mathrm{B}$ ratio, so this patient was not included in the study. The protein concentration of the CWP group (presented as mean \pm 1 standard deviation [SD], $\mathrm{n}=12$ ) before removal of the

Table I Age, anthropometric data, blood pressures, pressure pain thresholds, number of tender points, pain intensities, depressive and anxiety symptoms, catastrophizing, and quality of life in patients with CWP and in CON

\begin{tabular}{|c|c|c|c|c|c|}
\hline \multirow{2}{*}{$\begin{array}{l}\text { Group } \\
\text { Variables }\end{array}$} & \multicolumn{2}{|c|}{ CON, $n=13$} & \multicolumn{2}{|c|}{ CWP, $n=12$} & \multirow{2}{*}{$\begin{array}{l}\text { Statistics } \\
\text { p-Value }\end{array}$} \\
\hline & Mean & SD & Mean & SD & \\
\hline Age & 39.77 & 15.64 & 48.25 & 10.35 & 0.127 \\
\hline Weight (kg) & 63.50 & 8.93 & 85.04 & 19.88 & 0.002 \\
\hline Height (m) & 1.65 & 0.07 & 1.68 & 0.07 & 0.295 \\
\hline BMI $\left(\mathrm{kg} / \mathrm{m}^{2}\right)$ & 23.4 & 2.6 & 30.1 & 5.9 & 0.001 \\
\hline BP diastolic $(\mathrm{mmHg})$ & 74 & 7 & 84 & 6 & 0.001 \\
\hline BP systolic $(\mathrm{mmHg})$ & 120 & 9 & 132 & 14 & 0.023 \\
\hline PPT trapezius right $(\mathrm{kPa})$ & 291 & 59 & 120 & 46 & $<0.001$ \\
\hline PPT trapezius left $(\mathrm{kPa})$ & 268 & 57 & 143 & 123 & 0.003 \\
\hline PPT tibialis anterior $(\mathrm{kPa})$ & 466 & $|3|$ & 251 & 120 & $<0.001$ \\
\hline No. tender points & 0.8 & 1.0 & 13.6 & 3.2 & $<0.001$ \\
\hline Pain intensity neck (VAS) & 1 & 2 & 55 & 18 & $<0.001$ \\
\hline Pain intensity shoulders (VAS) & 2 & 6 & 67 & 18 & $<0.001$ \\
\hline Pain intensity arms (VAS) & 2 & 6 & 52 & 22 & $<0.001$ \\
\hline Pain intensity hands (VAS) & 0 & 0 & 43 & 25 & $<0.001$ \\
\hline Pain intensity upper back (VAS) & 0 & 0 & 58 & 27 & $<0.001$ \\
\hline Pain intensity lower back (VAS) & 2 & 7 & 65 & 23 & $<0.001$ \\
\hline Pain intensity hips (VAS) & 1 & 2 & 63 & 31 & $<0.001$ \\
\hline Pain intensity knees (VAS) & 4 & 13 & 41 & 22 & $<0.001$ \\
\hline Pain intensity feet (VAS) & 0 & 0 & $4 I$ & 28 & $<0.001$ \\
\hline HADS-A & 2.3 & 3.0 & 6.6 & 4.2 & 0.007 \\
\hline HADS-D & 0.9 & 1.3 & 5.9 & 3.6 & $<0.001$ \\
\hline PCS & 3.5 & 4.5 & 21.8 & 13.4 & $<0.001$ \\
\hline QOLS & 94.0 & 10.4 & 76.8 & 11.7 & 0.001 \\
\hline
\end{tabular}

Notes: Mean \pm I SD is given for each variable. Furthest to the right is the result of the statistical comparisons between the two groups ( $p$-value).

Abbreviations: CWP, chronic widespread pain; CON, healthy controls; SD, standard deviation; BMI, body mass index; PPT, pressure pain threshold; BP, blood pressure; VAS, visual analog scale; HADS-A, Hospital Anxiety and Depression Scale - subscale anxiety; HADS-D, Hospital Anxiety and Depression Scale - subscale depression; PCS, Pain Catastrophizing Scale; QOLS, Quality of Life Scale. 
albumin and IgG (i.e., "raw" CSF) was $370 \pm 94$ and after removal was $90 \pm 21$. The protein concentration of the CON group (presented as mean $\pm 1 \mathrm{SD}, \mathrm{n}=13$ ) before and after removal of the albumin and $\operatorname{IgG}$ was $266 \pm 53$ and $60 \pm$ 22 , respectively. After the removal of the abundant proteins albumin and IgG, several other proteins could be revealed on the 2-DE, revealing many low abundant proteins or proteins in a higher quantity (Figure $1 \mathrm{~A}$ and $\mathrm{B}$ ).

\section{Multivariate data analysis}

From the quantification of the 2-DE images, 481 proteins were matched between the gels and eligible for multivariate statistics. As a quality check of outliers, we computed an unsupervised PCA with five principal components $\left(R^{2}\right.$ (cumulative $)=0.43, Q^{2}$ (cumulative $\left.)=0.13\right)$, which revealed no moderate (distance to the model in X-space [DModX]) or strong outliers (Hotelling's $T^{2}$ statistic test [ $T^{2}$ Critical 99\%]).
To identify the proteins important for group separation of the subjects into CWP and CON, an OPLS-DA regression model (one predictive and two orthogonal latent variables, respectively; Figure 2) was generated. The result showed both excellent fit $\left(R^{2}=0.98\right)$ and prediction $\left(Q^{2}=0.91\right)$. The CV-ANOVA revealed that the model was highly significant $(p=0.00000118)$.

A total of 48 protein spots had a VIP $>1$, so these were considered important for the group separation (Figure 3; Table $\mathrm{S} 1)$. The most important protein spots for the discrimination (VIP $>1.3, p$ (corr) $>0.4 ; 11$ of 48 proteins) between the two groups are marked with a circle in Figure 3 and presented in Table 2.

A final OPLS-DA model (one predictive and one orthogonal latent variable) was computed using the 11 proteins in Table 2 as regressors. This regression also had a very good fit $\left(R^{2}=0.89\right)$ and had high predictivity $\left(Q^{2}=0.84\right)$.

\section{A}

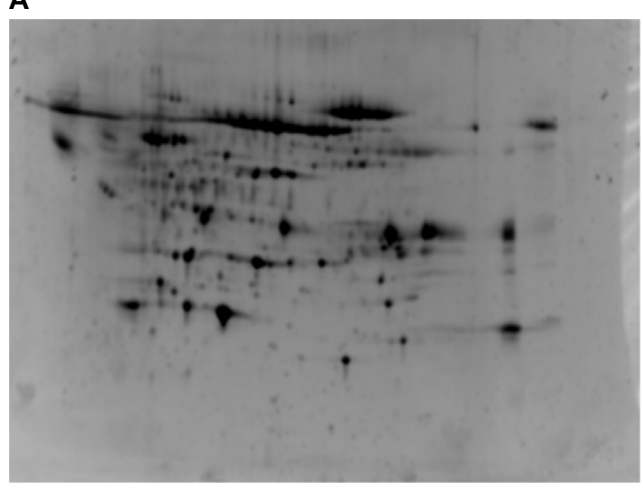

B

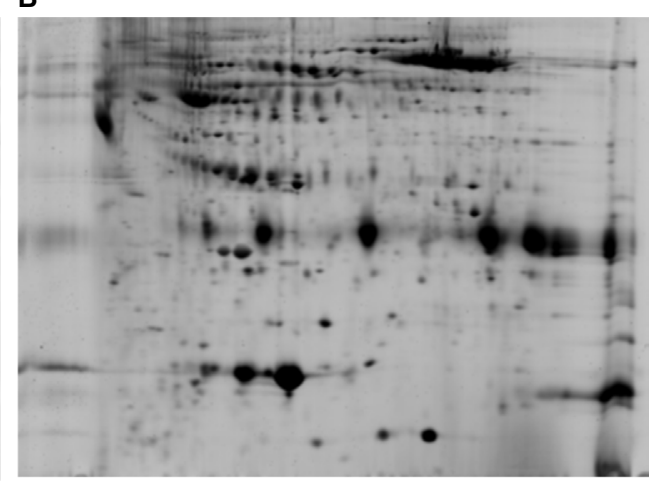

Figure I Images of CSF before and after albumin/lgG removal.

Notes: The figure shows the "raw" CSF (A) compared to the fractionated CSF (B).

Abbreviations: CSF, cerebrospinal fluid; lgG, immunoglobulin G.

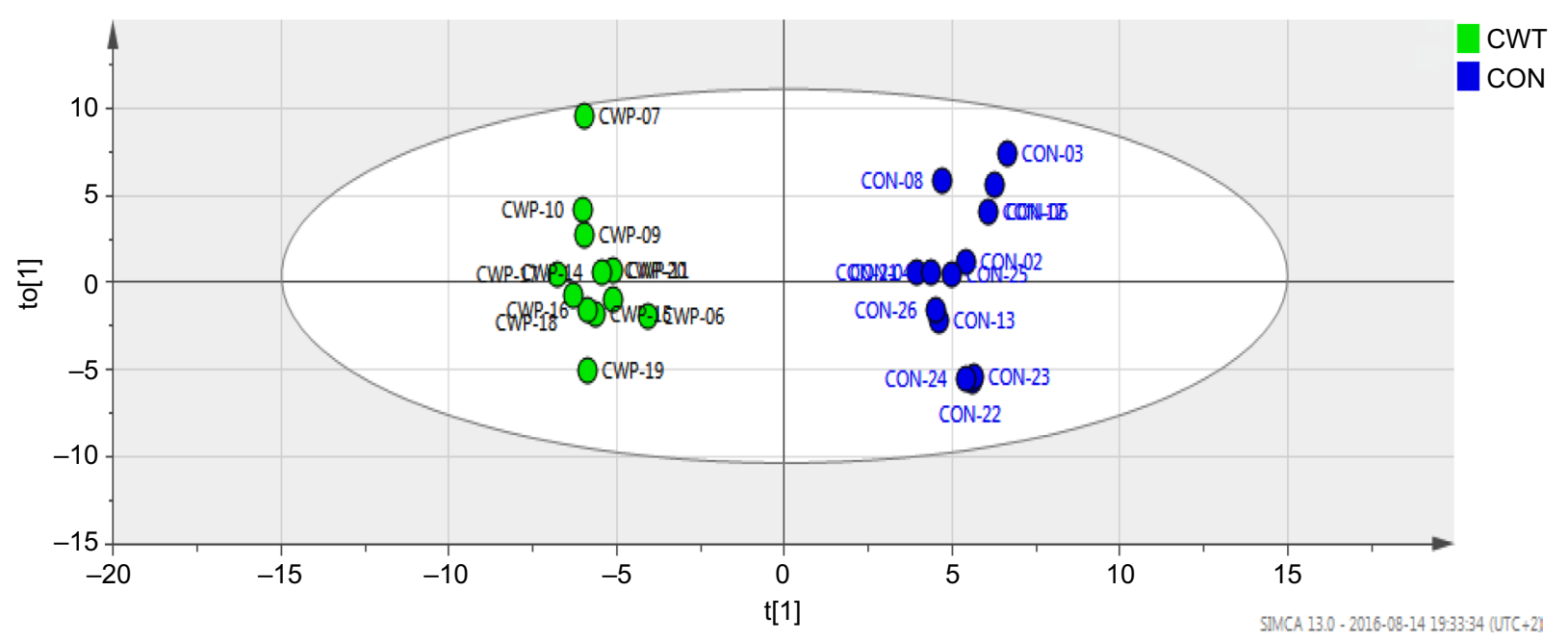

Figure 2 An OPLS-DA (the first principal component $t[I]$ vs. the first orthogonal component to[I]) model showing the discriminant separation between the CWP patients (green filled circles) and the CON (blue filled circles).

Notes: The longitudinal dimension (Y-axis) shows the interclass discrimination, and the latitudinal dimension (X-axis) shows the intraclass discrimination between CWP and CON.

Abbreviations: OPLS-DA, orthogonal partial least square discriminant analysis; CWP, chronic widespread pain; CON, healthy controls. 


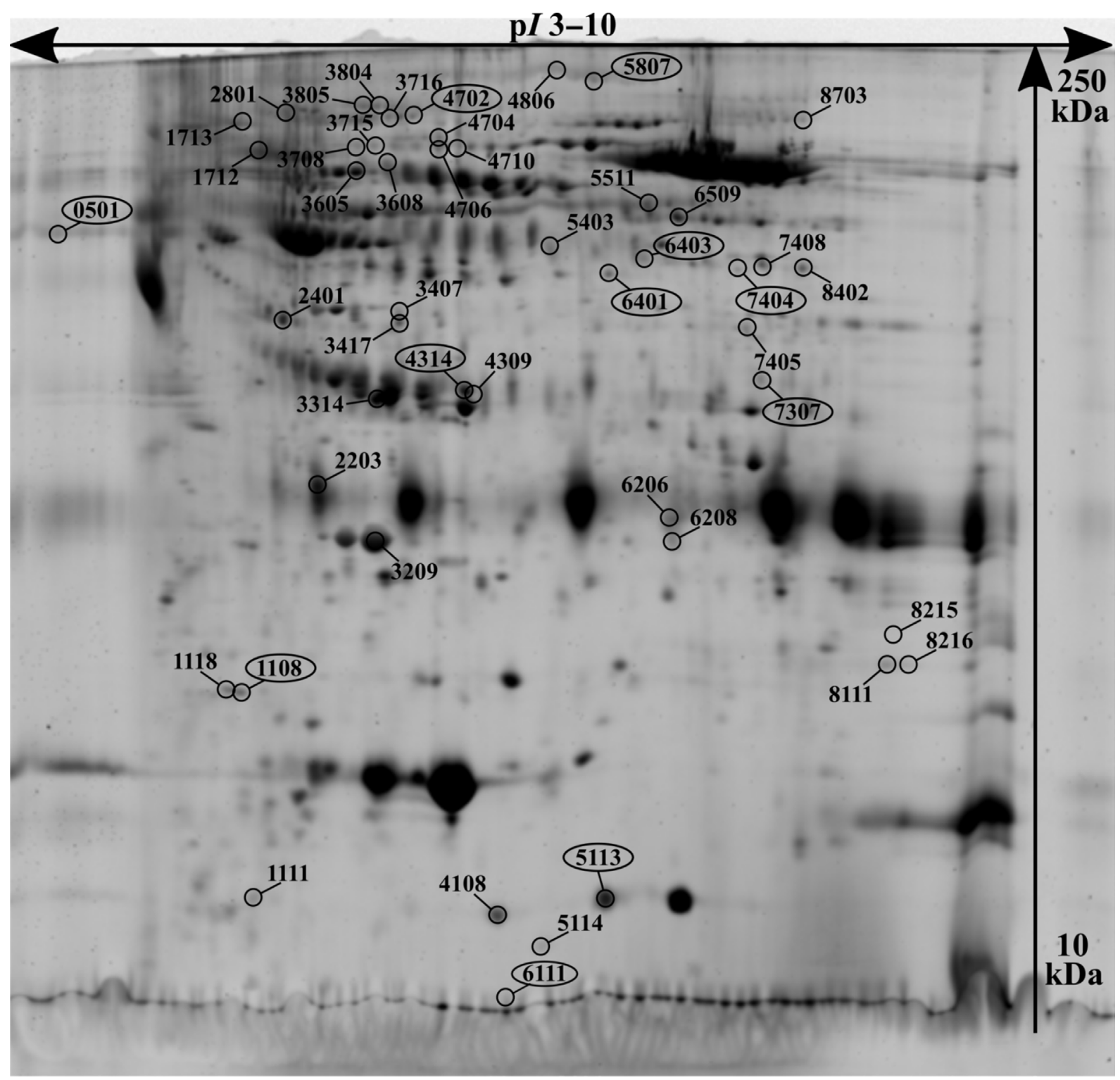

Figure 3 The 2-DE CSF proteins.

Notes: The image shows the proteins important for the group separation between CWP and CON. Protein numbers that are circled had a VIP>I.3 and were highly significant for the model.

Abbreviations: 2-DE, two-dimensional gel electrophoresis; CSF, cerebrospinal fluid; CWP, chronic widespread pain; CON, healthy controls; VIP, variable of importance.

This model was also highly significant according to CVANOVA ( $p=0.0000000756)$. Hence, clear group separation was achieved when only including these 11 proteins as regressors.

\section{Protein identification}

The 48 protein spots that were important for the separation between CWP and CON (VIP>1) were excised from the gel and in-gel digested by trypsin for identification by mass spectrometry. The protein spots that were highly stained were identified by MALDI-TOF, and the remaining protein spots of low abundance were identified by Orbitrap mass spectrometer. For most identified proteins, the apparent molecular mass and $\mathrm{p} I$ determined in the 2-DE were in agreement with the theoretical values. When identifying fragments of proteins (spot no. 1111), the position of the matched peptides within the theoretical sequence of the protein were controlled in UniProt database using "Compute $\mathrm{MW} / \mathrm{p} I$ " to be in agreement with the apparent $\mathrm{MW} / \mathrm{p} I$ on the gel. The identified proteins were grouped based on biological processes according to UniProt database (Tables 2 and S1); $19 \%$ of the significant proteins were expressed in more than one form, i.e., isoforms (alpha-2-macroglobulin [ $\alpha 2 \mathrm{M}]$, apolipoprotein E, beta-2-glycoprotein 1, alpha-1B-glycoprotein, prostaglandin-H2 D-isomerase, and beta-2-microglobulin form $\mathrm{p}$ 5.3, Contactin-1) (Table S1). 
Table 2 The most important proteins (VIP>I.3) discriminating between CWP and CON according to the OPLS-DA

\begin{tabular}{lllllll}
\hline Spot number & Protein & VIP & p(corr) & CoeffCS & IOD ratio (CWP/CON) & Type \\
\hline 6111 & Insulin-like growth factor II & 2.00 & -0.95 & + & 24.40 & $\mathrm{M}$ \\
$5807^{*}$ & Alpha-2-macroglobulin & 1.66 & 0.64 & - & 0.26 & $\mathrm{~S} \& \mathrm{l}$ \\
7404 & Alpha-enolase & 1.56 & 0.61 & - & 0.28 & $\mathrm{M}$ \\
5113 & Beta-2-microglobulin & 1.54 & -0.75 & + & 2.23 & $\mathrm{~S} \& \mathrm{l}$ \\
4314 & Transthyretin & 1.47 & 0.72 & - & 0.19 & $\mathrm{~T}$ \\
$1108^{*}$ & Beta-2-microglobulin form pl 5.3 & 1.45 & 0.67 & - & 0.33 & $\mathrm{~S} \& 1$ \\
4702 & Neuronal cell adhesion molecule & 1.37 & 0.44 & - & 0.36 & $\mathrm{~T}$ \\
6401 & Pigment epithelium-derived factor & 1.36 & 0.56 & - & 0.68 & $\mathrm{R}$ \\
6403 & Beta-I,4-glucuronyltransferase I & 1.34 & 0.58 & - & 0.56 & $\mathrm{M}$ \\
7307 & Malate dehydrogenase, cytoplasmic & 1.34 & 0.53 & - & 0.59 & $\mathrm{M}$ \\
0501 & Dickkopf-related protein 3 & 1.32 & 0.68 & - & 0.42 & $\mathrm{R}$ \\
\hline
\end{tabular}

Notes: For the CoeffCS, “+” indicates upregulation and "-" indicates downregulation of the protein in the CWP group compared to the CON. Spot numbers marked with * were present as an isoform on the 2-DE. The proteins were divided based on UniProt database (http://web.expasy.org) definition on biological process in different groups (labeled Type): M, metabolic; S\&l, stress and inflammatory; T, transport; R, regulation proteins.

Abbreviations: VIP, variable of importance; CWP, chronic widespread pain; CON, healthy controls; OPLS-DA, orthogonal partial least squares discriminant analysis; IOD, integrated optical density; CoeffCS, scaled and centered coefficients.

\section{Discussion}

Using 2-DE in combination with mass spectrometry, we separated and identified proteins in CSF from women with CWP and healthy female subjects. MVDA was used to determine the most important proteins for the separation of the two groups, and 48 of 481 proteins contributed significantly to the separation between CWP and CON; this highly significant OPLS-DA model had nearly perfect fit and predictivity $\left(R^{2}=0.98\right.$ and $\left.Q^{2}=0.91\right)$. The following discussion highlights the most significant proteins (i.e., those with a VIP $>1.3$ and a $p$ (corr) $>0.4$ ) (Table 2 ); the significant OPLS-DA model only using these 11 proteins as regressors was also characterized by a very good fit and predictivity $\left(R^{2}=0.89\right.$ and $\left.Q^{2}=0.84\right)$.

The protein with the highest discriminating power $(\mathrm{VIP}=2.0)$ was the insulin-like growth factor II (IGF2). It was upregulated in the CWP group. IGF2 is a protein that controls growth activity and in cultured cells triggers mitosis. ${ }^{59}$ It also has anti-apoptotic properties and inhibits apoptotic cell death (e.g., via antagonizing activation of pro-inflammatory cytokine signaling). ${ }^{60,61}$ Furthermore, pulsed radiofrequency right after nerve injury inhibited the development of neuropathic pain. This was found to be due to downregulation of IGF2 and the inhibition of ERK1/2 activity in microglial cells. ${ }^{62}$

The $\alpha 2 \mathrm{M}$ is a protease inhibitor and belongs to the I39 family of macroglobulins. It is synthesized by numerous cell lineages including astrocytes. ${ }^{63}$ It inhibits by trapping the protease after a conformational change has been triggered in the protein when the protease cleaves $\alpha 2 \mathrm{Ms}$ bait region. ${ }^{64}$ Thus, a strong covalent binding is made through the hydrolyzation of a thioester bond. Although the protease almost remains totally inhibited to the higher MW substrates, it is still able to cleave the substrates with lower MWs. The $\alpha 2 \mathrm{M}$ binds several cytokines (e.g., IL-6 and IL-1 $\beta$ ), growth factors (e.g., NGF and platelet-derived growth factor), and hormones ${ }^{63,64}$ It is considered as an acute-phase protein, ${ }^{65}$ and it has been suggested that $\alpha 2 \mathrm{M}$ has antioxidant effects and anti-inflammatory ability. ${ }^{63}$ With respect to the latter suggestion, the formation of the $\alpha 2 \mathrm{M}$-pro-inflammatory cytokine complex has been suggested to protect from the immediate toxic effect of cytokines. Increased levels of $\alpha 2 \mathrm{M}$ have been associated with dysfunctional blood-CSF barrier. ${ }^{66}$ This protein was downregulated in the present CWP cohort. Significantly lower levels of $\alpha 2 \mathrm{M}$ were also found in CSF from patients with schizophrenia, in subjects with risk of psychosis, and in depressed patients. .7,68 $^{67}$

Alpha-enolase is a multifunctional protein found in almost all human tissues. It is a metabolic enzyme as well as an important protein involved in growth control and allergic responses and stimulates immunoglobulin production. Alphaenolase has also been described as a hypoxic stress protein, a heat shock protein, and a neurotrophic factor. ${ }^{69}$ It has been characterized as a marker of pathological stress ${ }^{70}$ and as a biomarker of damaged glial cells. ${ }^{70}$ During ontogenesis, there is a transition from the alpha/alpha homodimer to the alpha/beta heterodimer in striated muscle cells and to the alpha/gamma heterodimer in nerve cells. Alpha-enolase was downregulated in the present CWP group. Previous studies found increased CSF levels in patients with multiple sclerosis, cerebral infarction, and peripheral neuropathy. ${ }^{70}$

$\beta$-2-Microglobuline was upregulated in the present CWP cohort. It is a small membrane protein of $\sim 11 \mathrm{kDa}$ expressed widely in all body fluids. ${ }^{71}$ Increased levels of CSF have been associated with an activation of the immune system, and it has been proposed as a reliable CSF biomarker of different inflammatory disorders or neoplastic CNS disorders (e.g., purulent meningitis, leptomeningeal metastasis, viral 
meningitis/encephalitis, and neuroborreliosis in CSF). ${ }^{72}$ After acute nociception (i.e., non-neurological surgery), significant increases in CSF $\beta$-2-microglobuline, but not in serum, were noted, which was ascribed to increased cellular turnover and immunological activation in CNS but not to peripheral inflammatory activity or changes in blood-brain barrier permeability. ${ }^{73}$ A significant increase in CSF $\beta$-2-microglobuline has also been found in chronic fatigue, chronic fatigue syndrome, and depression. ${ }^{68,74}$ In a relatively small study, an age dependence (i.e., higher CSF levels) was reported for subjects $>50$ years. ${ }^{75} \beta$-2-microglobuline has also been investigated in several studies of Alzheimer's disease and multiple sclerosis, but yet no consistent patterns have been established. ${ }^{76-79}$ Partially, in contrast to the results of this study, no differences were found in CSF levels between patients with polyneuritis/ polyneuropathies and $\mathrm{CON}$, which the authors suggested could have been due to heterogeneity aspects. ${ }^{72}$

Transthyretin (TTR; originally labeled prealbumin) has an MW of $55 \mathrm{kDa}$ and binds thyroxine (T4) and is secreted into the CSF by the choroid plexus. Most likely, it stands for the transportation of T4 to the CSF and the brain. ${ }^{80-82}$ It has also been suggested that TTR acts as an endogenous antiinflammatory mediator. ${ }^{83}$ It was downregulated in the present CWP group. Low level of TTR in CSF has been reported to correlate with depression and low serotonin function. ${ }^{68,84}$ Decreased CSF levels have been found in patients with firstonset schizophrenia. ${ }^{85}$ This protein was also of significant importance but upregulated in a proteomic study of CSF in patients with neuropathic pain. ${ }^{45}$ Increased CSF levels of TTR in response to oxidative stress have been reported. ${ }^{86}$ TTR has also been investigated in CSF from Alzheimer's disease, and both significant up- and downregulations have been reported. ${ }^{76}$

Neuronal cell adhesion molecule (NCAM, also called CD56) is part of the immunoglobulin superfamily mediating calcium-independent intercellular adhesion. This glycoprotein plays a part in the development of the nervous system and is involved in the increase of T cells and dendritic cells, which are of importance in the surveillance of the immune system. ${ }^{87} \mathrm{NCAM}$ participates in contact-mediated interactions among neurons, astrocytes, oligodendrocytes, and myotubes $^{88}$ and in plasticity of synaptic connection in memory formation, learning, and CNS injury repair. ${ }^{88,89} \mathrm{NCAM}$ was downregulated in CWP. CSF NCAM was also significantly lower in polyneuropathy compared to $\mathrm{CON} ;{ }^{90}$ low NCAM levels were suggested to represent extensive neuronal damage or lowered potential for endogenous repair due to chronicity or neurodegenerative etiology. Significant reductions have also been reported for multiple sclerosis, Alzheimer's disease, and meningitis. ${ }^{90}$ Both increased and decreased levels of this protein in CSF have been reported for subjects with depression. ${ }^{68,91}$ Animal experiments have shown changes in the expression patterns of NCAM isoforms that occur in the spinal cord as a consequence of peripheral injury and regeneration, ${ }^{92,93}$ which may indicate that NCAM participates in the reorganization of neural circuitry in the spinal cord. ${ }^{89}$

Pigment epithelium-derived factor (PEDF) is found in many tissues and fluids in the body (e.g., CNS and CSF). ${ }^{94}$ PEDF has neurotrophic, neuroprotective, and anti-oxidative properties. ${ }^{95-98}$ Although a member of the serpin (serine antiprotease) protein family, PEDF does not possess this activity. ${ }^{97}$ The protein has been described as having a neuroprotective effect from degeneration due to overexcitation by glutamate. ${ }^{96}$ Glutamate, through the $N$-methyl-D-aspartate receptor activation, can cause cell damage, resulting in an increase of nitric oxide (NO). This in turn will accumulate toxic peroxynitriles that form pro-apoptotic complexes with reactive oxygen species following apoptosis. ${ }^{96}$ Whether PEDF is anti-angiogenic or neurotrophic depends on the site and number of phosphorylations. ${ }^{94}$ PEDF was downregulated in CWP. Downregulations of this protein have been reported in CSF studies of neuropathic pain conditions. ${ }^{41,45}$ Whether it is up- or downregulated in depression is unclear. ${ }^{68}$

Beta-1,4-glucuronyltransferase was downregulated in CWP. It has its optimum $\mathrm{pH}$ at 7.0 and is involved in protein glycosylation, and in adults, it is highly expressed in brain, heart, and skeletal muscles. ${ }^{99}$ Mutations of the beta-1,3- $N$ acetylglucosaminyltransferase 1 have been reported to cause congenital muscular dystrophies. ${ }^{100}$

Malate dehydrogenase is a cellular enzyme and has an oxidoreductase activity and is involved in the production of NO through nicotinamide adenine dinucleotide phosphate in the mitochondria. NO is a highly diffusible messenger that is involved in many biological functions including modulation of nociception, immune function, and neurotransmission. ${ }^{101,102}$ Malate dehydrogenase is stimulated by dehydroepiandrosterone and thyroid-free T3. Furthermore, it has also been suggested to be associated with the pain modulation in FMS. ${ }^{103}$ It was downregulated in CWP. Decrease of malate dehydrogenases leads to lower levels of malate, and it has been reported that a supplemental use of malic acid can improve pain conditions in FMS. ${ }^{104}$ A mouse study of global cerebral ischemia has reported decreased levels of this protein in the spinal cord. ${ }^{105}$ Significant elevations in CSF have been reported in Alzheimer's disease and in Lewy body dementia. ${ }^{106}$ 
The dickkopf-related protein 3 (dkk-3) is a $38-\mathrm{kDa}$ protein and counteracts Wnt signaling by inhibiting low-density lipoprotein receptor-related protein 5 and 6 interaction with Wnt. ${ }^{107}$ The dickkopf-related proteins play a significant role in vertebrate development by inhibiting the Wnt-regulated processes such as limb development, somitogenesis, and eye formation. ${ }^{107}$ There are also some evidence suggesting that dkk-3 has a role in the immune system. ${ }^{108}$ The dkk-3 was downregulated in the present CWP cohort. A recent study of patients with multiple sclerosis also reported a CSF downregulation of ddk-3. ${ }^{109}$ Recently, it was suggested that dkk-3 may be an $A \beta$-associated protein in Alzheimer's disease. ${ }^{110}$

In conclusion, the most important and significant proteins are involved in apoptotic regulations, anti-inflammatory and anti-oxidative processes, activity of the immune system, and endogenous repair. Taken together, these findings indicate the presence of neuroinflammation in chronic pain and especially CWP, a possibility suggested by other authors. ${ }^{110,111}$ Although a pattern of proteins clearly discriminating CWP and CON (Table 2) was found, our study cannot determine if these alterations are primarily due to CNS processes or secondary consequences of peripheral factors. In fact, our group reported prominent proteomic alterations in the interstitium of the trapezius muscle and in biopsies of the same muscle in another cohort of CWP patients and controls. ${ }^{12,113}$ Interestingly, when comparing the results of this study (Table 2) with a recently published similar study from our group on neuropathic pain patients, ${ }^{45}$ the top protein lists of the two studies partly overlap, TTR and PEDF being significant proteins in both studies. In addition, among the other significant proteins were partial overlaps between the two studies identified - i.e., prostaglandin- $\mathrm{H} 2 \mathrm{~d}$-isomerase (downregulated in both conditions), gelsolin (downregulated in both conditions), apolipoprotein-A-I (generally upregulated in neuropathic pain but downregulated in the CWP), and haptoglobin (upregulated in both conditions) (Table S1). This might reflect, on the one hand, that different chronic pain conditions share common mechanisms but, on the other hand, that there are pain condition-specific mechanisms at work (in this case, in CWP vs. posttraumatic peripheral neuropathic pain). The most important proteins in this study have also been investigated and/or been identified in proteomic studies of neurodegenerative and psychiatric conditions. Hence, some of the alterations reported in pain and neurodegenerative and psychiatric conditions may be general and unspecific and not disease/condition specific.

This explorative study has several limitations. The number of subjects in each group was relatively low, although most proteomic studies of CSF in humans are relatively limited with respect to the number of subjects. The use of MVDA has several advantages in proteomic studies as mentioned in the "Introduction" section - e.g., the ability to handle the fact that the ratio between subjects $(12+13=25$ subjects) and variables (481 proteins) was low. Moreover, selection mechanisms may have been present in the group of patients such as overrepresentation of patients with severe CWP. Although we have investigated patients with CWP, they had low levels of psychological strain. This explorative study must be confirmed in larger studies that also include different groups of chronic pain conditions (e.g., with respect to degree of pain spreading on the body). Future studies should be larger and include analyses of possible confounders and to what extent pain and depression, e.g., may share inflammation as a common mediator. ${ }^{110}$ Determination of unique and common regressors may also be applicable for factors such as BMI, concomitant medication, and blood pressures. ${ }^{114}$ The comparisons with proteomic studies concerning neurodegenerative and psychiatric conditions made earlier may be biased since several of these studies have not determined the most important proteins using MVDA or similar techniques. Thus, the discriminating and predictive ability of potentially interesting proteins was not considered.

\section{Conclusion}

In this explorative study, we used proteomics in combination with MVDA and found 48 proteins in CSF that were important in discriminating women with CWP from CON. The highest discriminating proteins (11 proteins) are, according to the literature, involved in apoptotic regulations, anti-inflammatory and anti-oxidative processes, activity of the immune system, and endogenous repair. Our results suggest the presence of neuroinflammation in the CNS of CWP patients. Future studies should include more participants, control for confounders, and determine which alterations are unspecific/general and which are specific changes.

\section{Acknowledgments}

We gratefully appreciate the people who donated CSF for this study, and we would like to thank nurses Marie Berggården, Anna Peterson, and Eva-Britt Lindh for their valuable help with the sample collection. This study was supported by the Swedish Research Council (K2015-99x-21874-05-4), Medical Research Council of Southeast Sweden (FORSS-159031), Region Östergötland (LIO-35923, SC-2013-00395-36), and AFA Insurance (140341). The funders had no role in study 
design, data collection and analysis, decision to publish, or preparation of the manuscript.

\section{Disclosure}

The authors report no conflicts of interest in this work.

\section{References}

1. Croft P, Burt J, Schollum J, Thomas E, Macfarlane G, Silman A. More pain, more tender points: is fibromyalgia just one end of a continuous spectrum? Ann Rheum Dis. 1996;55(7):482-485.

2. Grimby-Ekman A, Gerdle B, Björk J, Larsson B. Comorbidities, intensity, frequency and duration of pain, daily functioning and health care seeking in local, regional, and widespread pain - a descriptive population-based survey (SwePain). BMC Musculoskelet Disord. 2015;16:165.

3. Peolsson M, Borsbo B, Gerdle B. Generalized pain is associated with more negative consequences than local or regional pain: a study of chronic whiplash-associated disorders. J Rehabil Med. 2007; 39(3):260-268.

4. Mayer TG, Towns BL, Neblett R, Theodore BR, Gatchel RJ. Chronic widespread pain in patients with occupational spinal disorders: prevalence, psychiatric comorbidity, and association with outcomes. Spine (Phila Pa 1976). 2008;33(17):1889-1897.

5. Schaefer C, Chandran A, Hufstader M, et al. The comparative burden of mild, moderate and severe fibromyalgia: results from a cross-sectional survey in the United States. Health Qual Life Outcomes. 2011;9:71.

6. Kamaleri Y, Natvig B, Ihlebaek CM, Benth JS, Bruusgaard D. Number of pain sites is associated with demographic, lifestyle, and health-related factors in the general population. Eur J Pain. 2008;12(6):742-748.

7. Gerdle B, Björk J, Cöster L, Henriksson K, Henriksson C, Bengtsson A. Prevalence of widespread pain and associations with work status: a population study. BMC Musculoskelet Disord. 2008;9:102.

8. Mansfield KE, Sim J, Jordan JL, Jordan KP. A systematic review and meta-analysis of the prevalence of chronic widespread pain in the general population. Pain. 2016;157(1):55-64.

9. Butler S, Landmark T, Glette M, Borchgrevink P, Woodhouse A. Chronic widespread pain-the need for a standard definition. Pain. 2016; 157(3):541-543.

10. Jensen KB, Loitoile R, Kosek E, et al. Patients with fibromyalgia display less functional connectivity in the brain's pain inhibitory network. Mol Pain. 2012;8:32.

11. Nijs J, Kosek E, Van Oosterwijck J, Meeus M. Dysfunctional endogenous analgesia during exercise in patients with chronic pain: to exercise or not to exercise? Pain Physician. 2012;15(3 suppl):ES205-ES213.

12. Petersel DL, Dror V, Cheung R. Central amplification and fibromyalgia: disorder of pain processing. J Neurosci Res. 2011;89(1):29-34.

13. Heinrichera MM, Tavaresc I, Leith JL, Lumbe BM. Descending control of nociception: specificity, recruitment and plasticity. Brain Res Rev. 2009;60(1):214-225.

14. Adler GK, Geenen R. Hypothalamic-pituitary-adrenal and autonomic nervous system functioning in fibromyalgia. Rheum Dis Clin North Am. 2005;31(1):187-202,xi.

15. Dessein PH, Shipton EA, Stanwix AE, Joffe BI. Neuroendocrine deficiency-mediated development and persistence of pain in fibromyalgia: a promising paradigm? Pain. 2000;86(3):213-215.

16. Bradley LA. Pathophysiology of fibromyalgia. Am J Med. 2009;122(12 suppl):S22-S30.

17. Smith H, Harris R, Clauw D. Fibromyalgia: an afferent processing disorder leading to a complex pain generalized syndrome. Pain Physician. 2011;14(2):E217-E245.

18. Gerdle B, Lemming D, Kristiansen J, Larsson B, Peolsson M, Rosendal L. Biochemical alterations in the trapezius muscle of patients with chronic whiplash associated disorders (WAD) - a microdialysis study. Eur $J$ Pain. 2008;12(1):82-93.

19. Üçeyler N, Zeller D, Kahn AK, et al. Small fibre pathology in patients with fibromyalgia syndrome. Brain. 2013;136(pt 6):1857-1867.
20. Oaklander AL, Herzog ZD, Downs HM, Klein MM. Objective evidence that small-fiber polyneuropathy underlies some illnesses currently labeled as fibromyalgia. Pain. 2013;154(11):2310-2316.

21. Serra J, Collado A, Solà R, et al. Hyperexcitable C nociceptors in fibromyalgia. Ann Neurol. 2014;75(2):196-208.

22. Bennett RM. Emerging concepts in the neurobiology of chronic pain: evidence of abnormal sensory processing in fibromyalgia. Mayo Clin Proc. 1999;74(4):385-398.

23. Staud R. The role of peripheral input for chronic pain syndromes like fibromyalgia syndrome. J Musculoskelet Pain. 2008;16(1-2):67-74.

24. Schneider GM, Smith AD, Hooper A, et al. Minimizing the source of nociception and its concurrent effect on sensory hypersensitivity: an exploratory study in chronic whiplash patients. BMC Musculoskelet Disord. 2010;11:29.

25. Staud R, Nagel S, Robinson ME, Price DD. Enhanced central pain processing of fibromyalgia patients is maintained by muscle afferent input: a randomized, double-blind, placebo-controlled study. Pain. 2009; 145(1-2):96-104.

26. Herren-Gerber R, Weiss S, Arendt-Nielsen L, et al. Modulation of central hypersensitivity by nociceptive input in chronic pain after whiplash injury. Pain Med. 2004;5(4):366-376.

27. Staud R, Robinson ME, Weyl EE, Price DD. Pain variability in fibromyalgia is related to activity and rest: role of peripheral tissue impulse input. J Pain. 2010;11(12):1376-1383.

28. Kosek E, Ekholm J, Hansson P. Modulation of pressure pain thresholds during and following isometric contraction in patients with fibromyalgia and in healthy controls. Pain. 1996;64(3):415-423.

29. Mannes AJ, Martin BM, Yang HY, et al. Cystatin C as a cerebrospinal fluid biomarker for pain in humans. Pain. 2003;102(3):251-256.

30. Romeo MJ, Espina V, Lowenthal M, Espina BH, Petricoin EF 3rd, Liotta LA. CSF proteome: a protein repository for potential biomarker identification. Expert Rev Proteomics. 2005;2(1):57-70.

31. Ortega E, García JJ, Bote ME, et al. Exercise in fibromyalgia and related inflammatory disorders: known effects and unknown chances. Exerc Immunol Rev. 2009;15:42-65.

32. Shevchenko G, Konzer A, Musunuri S, Bergquist J. Neuroproteomics tools in clinical practice. Biochim Biophys Acta. 2015;1854(7):705-717.

33. Johanson CE, Duncan JA 3rd, Klinge PM, Brinker T, Stopa EG, Silverberg GD. Multiplicity of cerebrospinal fluid functions: new challenges in health and disease. Cerebrospinal Fluid Res. 2008;5:10.

34. Russell IJ, Orr MD, Littman B, et al. Elevated cerebrospinal fluid levels of substance $\mathrm{P}$ in patients with the fibromyalgia syndrome. Arthritis Rheum. 1994;37(11):1593-1601.

35. Vaerøy H, Helle R, Førre O, Kåss E, Terenius L. Elevated CSF levels of substance $\mathrm{P}$ and high incidence of Raynaud phenomenon in patients with fibromyalgia: new features for diagnosis. Pain. 1988;32(1):21-26.

36. Bjurstrom MF, Giron SE, Griffis CA. Cerebrospinal fluid cytokines and neurotrophic factors in human chronic pain populations: a comprehensive review. Pain Pract. 2016;16(2):183-203.

37. Kalso E. Biomarkers for pain. Pain. 2004;107(3):199-201.

38. Wheelock AM, Wheelock CE. Trials and tribulations of 'omics data analysis: assessing quality of SIMCA-based multivariate models using examples from pulmonary medicine. Mol Biosyst. 2013;9(11):2589-2596.

39. Görg A, Drews O, Lück C, Weiland F, Weiss W. 2-DE with IPGs. Electrophoresis. 2009;30(suppl 1):S122-S132.

40. Liu XD, Zeng BF, Xu JG, Zhu HB, Xia QC. Proteomic analysis of the cerebrospinal fluid of patients with lumbar disk herniation. Proteomics. 2006;6(3):1019-1028.

41. Conti A, Ricchiuto P, Iannaccone S, et al. Pigment epithelium-derived factor is differentially expressed in peripheral neuropathies. Proteomics. 2005;5(17):4558-4567.

42. Lu J, Katano T, Nishimura W, et al. Proteomic analysis of cerebrospinal fluid before and after intrathecal injection of steroid into patients with postherpetic pain. Proteomics. 2012;12(19-20):3105-3112.

43. Pattini L, Mazzara S, Conti A, Iannaccone S, Cerutti S, Alessio M. An integrated strategy in two-dimensional electrophoresis analysis able to identify discriminants between different clinical conditions. Exp Biol Med (Maywood). 2008;233(4):483-491. 
44. Cannistraci CV, Ravasi T, Montevecchi FM, Ideker T, Alessio M. Nonlinear dimension reduction and clustering by Minimum Curvilinearity unfold neuropathic pain and tissue embryological classes. Bioinformatics. 2010;26(18):i531-i539.

45. Bäckryd E, Ghafouri B, Carlsson AK, Olausson P, Gerdle B. Multivariate proteomic analysis of the cerebrospinal fluid of patients with peripheral neuropathic pain and healthy controls - a hypothesisgenerating pilot study. J Pain Res. 2015;8:321-333.

46. Wolfe F, Smythe HA, Yunus MB, et al. The American College of Rheumatology 1990 criteria for the classification of fibromyalgia. Report of the Multicenter Criteria Committee. Arthritis Rheum. 1990; 33(2):160-172.

47. Sjörs A, Larsson B, Persson AL, Gerdle B. An increased response to experimental muscle pain is related to psychological status in women with chronic non-traumatic neck-shoulder pain. BMC Musculoskelet Disord. 2011;12:230.

48. Bjelland I, Dahl AA, Haug TT, Neckelmann D. The validity of the Hospital Anxiety and Depression Scale. An updated literature review. J Psychosom Res. 2002;52(2):69-77.

49. Zigmond AS, Snaith RP. The hospital anxiety and depression scale. Acta Psychiatr Scand. 1983;67(6):361-370.

50. Sullivan MJL, Bishop SR, Pivik J. The pain catastrophizing scale: development and validation. Psychol Assess. 1995;7:524-532.

51. Osman A, Barrios FX, Gutierrez PM, Kopper BA, Merrifield T, Grittmann L. The Pain Catastrophizing Scale: further psychometric evaluation with adult samples. J Behav Med. 2000;23(4):351-365.

52. Scott W, Wideman TH, Sullivan MJ. Clinically meaningful scores on pain catastrophizing before and after multidisciplinary rehabilitation: a prospective study of individuals with subacute pain after whiplash injury. Clin J Pain. 2014;30(3):183-190.

53. Burckhardt CS, Archenholtz B, Bjelle A. Measuring the quality of life of women with rheumatoid arthritis or systemic lupus erythematosus: a Swedish version of the Quality of Life Scale (QOLS). Scand J Rheumatol. 1992;21(4):190-195.

54. Osman I, Gaillard O, Meillet D, et al. A sensitive time-resolved immunofluorometric assay for the measurement of apolipoprotein B in cerebrospinal fluid. Application to multiple sclerosis and other neurological diseases. Eur J Clin Chem Clin Biochem. 1995;33(1):53-58.

55. Olausson P, Gerdle B, Ghafouri N, Sjöström D, Blixt E, Ghafouri B. Protein alterations in women with chronic widespread pain - an explorative proteomic study of the trapezius muscle. Sci Rep. 2015;5:11894.

56. Bradford MM. A rapid and sensitive method for the quantitation of microgram quantities of protein utilizing the principle of protein-dye binding. Anal Biochem. 1976;72:248-254.

57. Rosendal L, Larsson B, Kristiansen J, et al. Increase in muscle nociceptive substances and anaerobic metabolism in patients with trapezius myalgia: microdialysis in rest and during exercise. Pain. 2004; 112(3):324-334.

58. Eriksson L, Byrne T, Johansson E, Trygg J, Vikström C. Multi- and Megavariate Data Analysis: Basic Principles and Applications. 3rd revised ed. Malmö: MKS Umetrics AB; 2013.

59. Scalia P, Heart E, Comai L, Vigneri R, Sung CK. Regulation of the Akt/ Glycogen synthase kinase-3 axis by insulin-like growth factor-II via activation of the human insulin receptor isoform-A. J Cell Biochem 2001;82(4):610-618.

60. Hughes A, Mohanasundaram D, Kireta S, Jessup CF, Drogemuller CJ, Coates PT. Insulin-Like growth factor-II (IGF-II) prevents proinflammatory cytokine-induced apoptosis and significantly improves islet survival after transplantation. Transplantation. 2013;95(5): 671-678.

61. Hughes A, Rojas-Canales D, Drogemuller C, Voelcker NH, Grey ST, Coates PT. IGF2: an endocrine hormone to improve islet transplant survival. J Endocrinol. 2014;221(2):R41-R48.

62. Yeh CC, Sun HL, Huang CJ, et al. Long-term anti-allodynic effect of immediate pulsed radiofrequency modulation through down-regulation of insulin-like growth factor 2 in a neuropathic pain model. Int J Mol Sci. 2015;16(11):27156-27170.
63. Chen X, Kong X, Zhang Z, et al. Alpha-2-macroglobulin as a radioprotective agent: a review. Chin J Cancer Res. 2014;26(5):611-621.

64. Rehman AA, Ahsan H, Khan FH. alpha-2-Macroglobulin: a physiological guardian. J Cell Physiol. 2013;228(8):1665-1675.

65. Bhamra MS, Ashton NJ. Finding a pathological diagnosis for Alzheimer's disease: are inflammatory molecules the answer? Electrophoresis. 2012;33(24):3598-3607.

66. Kanoh Y, Ohtani H. Levels of interleukin-6, CRP and alpha 2 macroglobulin in cerebrospinal fluid (CSF) and serum as indicator of bloodCSF barrier damage. Biochem Mol Biol Int. 1997;43(2):269-278.

67. Hayes LN, Severance EG, Leek JT, et al. Inflammatory molecular signature associated with infectious agents in psychosis. Schizophr Bull. 2014;40(5):963-972.

68. Ditzen C, Tang N, Jastorff AM, et al. Cerebrospinal fluid biomarkers for major depression confirm relevance of associated pathophysiology. Neuropsychopharmacology. 2012;37(4):1013-1025.

69. Diaz-Ramos A, Roig-Borrellas A, García-Melero A, López-Alemany R. alpha-Enolase, a multifunctional protein: its role on pathophysiological situations. J Biomed Biotechnol. 2012;2012:156795

70. Royds JA, Davies-Jones GA, Lewtas NA, Timperley WR, Taylor CB. Enolase isoenzymes in the cerebrospinal fluid of patients with diseases of the nervous system. JNeurol Neurosurg Psychiatry. 1983;46(11):1031-1036.

71. Ohashi K, Hara M, Kawai R, et al. Cervical discs are most susceptible to beta 2-microglobulin amyloid deposition in the vertebral column. Kidney Int. 1992;41(6):1646-1652.

72. Svatoňová J, Bořecká K, Adam P, Lánská V. Beta2-microglobulin as a diagnostic marker in cerebrospinal fluid: a follow-up study. Dis Markers. 2014;2014:495402.

73. Anckarsäter R, Vasic N, Jidéus L, et al. Cerebrospinal fluid protein reactions during non-neurological surgery. Acta Neurol Scand. 2007;115(4): 254-259.

74. Buchwald D, Wener MH, Pearlman T, Kith P. Markers of inflammation and immune activation in chronic fatigue and chronic fatigue syndrome. J Rheumatol. 1997;24(2):372-376.

75. Kepplinger B, Baran H, Kainz A, Ferraz-Leite H, Newcombe J, Kalina P. Age-related increase of kynurenic acid in human cerebrospinal fluid - IgG and beta2-microglobulin changes. Neurosignals. 2005; 14(3):126-135.

76. Zellner M, Veitinger M, Umlauf E. The role of proteomics in dementia and Alzheimer's disease. Acta Neuropathol. 2009;118(1):181-195.

77. Matejčíková Z, Mareš J, Přikrylová Vranová H, et al. Cerebrospinal fluid inflammatory markers in patients with multiple sclerosis: a pilot study. J Neural Transm (Vienna). 2015;122(2):273-277.

78. Carrieri PB, Indaco A, Maiorino A, et al. Cerebrospinal fluid beta2-microglobulin in multiple sclerosis and AIDS dementia complex. Neurol Res. 1992;14(3):282-283.

79. Sladkova V, Mareš J, Lubenova B, et al. Degenerative and inflammatory markers in the cerebrospinal fluid of multiple sclerosis patients with relapsing-remitting course of disease and after clinical isolated syndrome. Neurol Res. 2011;33(4):415-420.

80. Herbert J, Wilcox JN, Pham KT, et al. Transthyretin: a choroid plexusspecific transport protein in human brain. The 1986 S. Weir Mitchell award. Neurology. 1986;36(7):900-911.

81. Chanoine JP, Alex S, Fang SL, et al. Role of transthyretin in the transport of thyroxine from the blood to the choroid plexus, the cerebrospinal fluid, and the brain. Endocrinology. 1992;130(2):933-938.

82. Chanoine JP, Braverman LE. The role of transthyretin in the transport of thyroid hormone to cerebrospinal fluid and brain. Acta Med Austriaca. 1992;19(suppl 1):25-28.

83. Rialland P, Otis C, de Courval ML, et al. Assessing experimental visceral pain in dairy cattle: a pilot, prospective, blinded, randomized, and controlled study focusing on spinal pain proteomics. J Dairy Sci. 2014;97(4):2118-2134.

84. Sullivan GM, Mann JJ, Oquendo MA, Lo ES, Cooper TB, Gorman JM. Low cerebrospinal fluid transthyretin levels in depression: correlations with suicidal ideation and low serotonin function. Biol Psychiatry. 2006;60(5):500-506. 
85. Huang JT, Leweke FM, Oxley D, et al. Disease biomarkers in cerebrospinal fluid of patients with first-onset psychosis. PLoS Med. 2006;3(11):e428.

86. Maetzler W, Tian Y, Baur SM, et al. Serum and cerebrospinal fluid levels of transthyretin in Lewy body disorders with and without dementia. PLoS One. 2012;7(10):e48042.

87. Strekalova H, Buhmann C, Kleene R, et al. Elevated levels of neural recognition molecule $\mathrm{L} 1$ in the cerebrospinal fluid of patients with Alzheimer disease and other dementia syndromes. Neurobiol Aging. 2006;27(1):1-9.

88. Weledji EP, Assob JC. The ubiquitous neural cell adhesion molecule (N-CAM). Ann Med Surg (Lond). 2014;3(3):77-81.

89. Sakai A, Asada M, Seno N, Suzuki H. Involvement of neural cell adhesion molecule signaling in glial cell line-derived neurotrophic factor-induced analgesia in a rat model of neuropathic pain. Pain. 2008;137(2):378-388.

90. Gnanapavan S, Grant D, Illes-Toth E, Lakdawala N, Keir G, Giovannoni G. Neural cell adhesion molecule - description of a CSF ELISA method and evidence of reduced levels in selected neurological disorders. J Neuroimmunol. 2010;225(1-2):118-122.

91. Jorgensen OS. Neural cell adhesion molecule (NCAM) and prealbumin in cerebrospinal fluid from depressed patients. Acta Psychiatr Scand Suppl. 1988;345:29-37.

92. Daniloff JK, Levi G, Grumet M, Rieger F, Edelman GM. Altered expression of neuronal cell adhesion molecules induced by nerve injury and repair. J Cell Biol. 1986;103(3):929-945.

93. Tzeng SF, Cheng H, Lee YS, Wu JP, Hoffer BJ, Kuo JS. Expression of neural cell adhesion molecule in spinal cords following a complete transection. Life Sci. 2001;68(9):1005-1012.

94. Abraham JD, Calvayrac-Pawlowski S, Cobo S, et al. Combined measurement of PEDF, haptoglobin and tau in cerebrospinal fluid improves the diagnostic discrimination between Alzheimer's disease and other dementias. Biomarkers. 2011;16(2):161-171.

95. Tombran-Tink J, Barnstable CJ. PEDF: a multifaceted neurotrophic factor. Nat Rev Neurosci. 2003;4(8):628-636.

96. Craword SE, Fitchev P, Veliceasa D, Volpert OV. The many facets of PEDF in drug discovery and disease: a diamond in the rough or split personality disorder? Expert Opin Drug Discov. 2013;8(7):769-792.

97. Baraniuk JN, Casado B, Maibach H, Clauw DJ, Pannell LK, Hess SS. A Chronic Fatigue Syndrome - related proteome in human cerebrospinal fluid. BMC Neurol. 2005;5:22.

98. Amano S, Yamagishi S, Inagaki Y, et al. Pigment epithelium-derived factor inhibits oxidative stress-induced apoptosis and dysfunction of cultured retinal pericytes. Microvasc Res. 2005;69(1-2):45-55.

99. Praissman JL, Live DH, Wang S, et al. B4GAT1 is the priming enzyme for the LARGE-dependent functional glycosylation of alphadystroglycan. Elife. 2014;3:e03943.

100. Buysse K, Riemersma M, Powell G, et al. Missense mutations in beta-1,3-N-acetylglucosaminyltransferase 1 (B3GNT1) cause WalkerWarburg syndrome. Hum Mol Genet. 2013;22(9):1746-1754.
101. Kingwell BA. Nitric oxide-mediated metabolic regulation during exercise: effects of training in health and cardiovascular disease. FASEBJ. 2000;14(12):1685-1696.

102. Akyol O, Zoroglu SS, Armutcu F, Sahin S, Gurel A. Nitric oxide as a physiopathological factor in neuropsychiatric disorders. In Vivo. 2004;18(3):377-390.

103. Larson AA, Giovengo SL, Russell IJ, Michalek JE. Changes in the concentrations of amino acids in the cerebrospinal fluid that correlate with pain in patients with fibromyalgia: implications for nitric oxide pathways. Pain. 2000;87(2):201-211.

104. Russell IJ, Michalek JE, Flechas JD, Abraham GE. Treatment of fibromyalgia syndrome with Super Malic: a randomized, double blind, placebo controlled, crossover pilot study. J Rheumatol. 1995;22(5): 953-958.

105. Harada S, Matsuura W, Takano M, Tokuyama S. Proteomic profiling in the spinal cord and sciatic nerve in a global cerebral ischemia-induced mechanical allodynia mouse model. Biol Pharm Bull. 2016;39(2): 230-238.

106. Heywood WE, Galimberti D, Bliss E, et al. Identification of novel CSF biomarkers for neurodegeneration and their validation by a highthroughput multiplexed targeted proteomic assay. Mol Neurodegener. 2015;10:64.

107. Ahn VE, Chu ML, Choi HJ, Tran D, Abo A, Weis WI. Structural basis of Wnt signaling inhibition by Dickkopf binding to LRP5/6. Dev Cell. 2011;21(5):862-873.

108. Bruggink KA, Kuiperij HB, Gloerich J, et al. Dickkopf-related protein 3 is a potential Abeta-associated protein in Alzheimer's Disease. J Neurochem. 2015;134(6):1152-1162.

109. Kroksveen AC, Guldbrandsen A, Vedeler C, Myhr KM, Opsahl JA, Berven FS. Cerebrospinal fluid proteome comparison between multiple sclerosis patients and controls. Acta Neurol Scand. 2012;126:90-96.

110. Walker AK, Kavelaars A, Heijnen CJ, Dantzer R. Neuroinflammation and comorbidity of pain and depression. Pharmacol Rev. 2014;66(1): 80-101.

111. Kosek E, Altawil R, Kadetoff D, et al. Evidence of different mediators of central inflammation in dysfunctional and inflammatory pain - interleukin-8 in fibromyalgia and interleukin-1 beta in rheumatoid arthritis. J Neuroimmunol. 2015;280:49-55.

112. Olausson P, Gerdle B, Ghafouri N, Larsson B, Ghafouri B. Identification of proteins from interstitium of trapezius muscle in women with chronic myalgia using microdialysis in combination with proteomics. PLoS One. 2012;7(12):e52560.

113. Olausson P, Gerdle B, Ghafouri N, Sjöström D, Blixt E, Ghafouri B. Protein alterations in women with chronic widespread pain - an explorative proteomic study of the trapezius muscle. Sci Rep. 2015;5:11894.

114. González-Marrero I, Castañeyra-Ruiz L, González-Toledo JM, et al. High blood pressure effects on the blood to cerebrospinal fluid barrier and cerebrospinal fluid protein composition: a two-dimensional electrophoresis study in spontaneously hypertensive rats. Int J Hypertens. 2013;2013:164653. 


\section{Supplementary material}

Table SI Altered proteins in cerebrospinal fluid identified by 2-DE and nLC-MS/MS.

\begin{tabular}{|c|c|c|c|c|c|c|}
\hline $\begin{array}{l}\text { Spot } \\
\text { number }\end{array}$ & Protein name & $\begin{array}{l}\text { Accession } \\
\text { number }\end{array}$ & $\mathrm{MW}(\mathrm{kDa}) / \mathrm{pl}$ & $\begin{array}{l}\text { Matched } \\
\text { unique } \\
\text { peptides }\end{array}$ & $\begin{array}{l}\text { Sequence } \\
\text { coverage (\%) }\end{array}$ & $\begin{array}{l}\text { IOD ratio } \\
\text { (CWPI } \\
\text { CON) }\end{array}$ \\
\hline 6111 & Insulin-like growth factor II & P0I344 & $20.1 / 6.4$ & 2 & 13.9 & 24.4 \\
\hline 5807 & Alpha-2-macroglobulin & P0I023 & $163.3 / 6.0$ & 20 & 16.9 & 0.26 \\
\hline 7404 & Alpha-enolase & P06733 & $47.2 / 7.0$ & 18 & 46.1 & 0.28 \\
\hline 5113 & Beta-2-microglobulin & P61769 & $13.7 / 6.1$ & 5 & 31.1 & 2.23 \\
\hline 4314 & Transthyretin & P02766 & $15.9 / 5.3$ & 8 & 72.8 & 0.19 \\
\hline 1108 & Beta-2-microglobulin form p/ 5.3 & P61769 & $13.7 / 5.3$ & 2 & 16.8 & 0.33 \\
\hline 4702 & Neuronal cell adhesion molecule & Q92823 & $143.9 / 5.3$ & 20 & 16.9 & 0.36 \\
\hline 6401 & Pigment epithelium-derived factor & P36955 & $46.3 / 5.9$ & 6 & 16.3 & 0.68 \\
\hline 6403 & Beta-I,4-glucuronyltransferase I & O43505 & $47.1 / 6.8$ & 5 & 11.8 & 0.56 \\
\hline 7307 & Malate dehydrogenase, cytoplasmic & P40925 & $36.4 / 6.9$ & 12 & 35 & 0.59 \\
\hline 0501 & Dickkopf-related protein 3 & Q9UBP4 & $38.4 / 4.5$ & 6 & 21.4 & 0.42 \\
\hline 2801 & Voltage-dependent calcium channel subunit alpha-2/delta-I & P54289 & $124.6 / 5.1$ & 27 & 25.6 & 0.15 \\
\hline 8111 & Prostaglandin- $\mathrm{H} 2 \mathrm{~d}$-isomerase & P4I222 & $21.0 / 8.4$ & 4 & 31.1 & 0.44 \\
\hline 3605 & Alpha-IB-glycoprotein & P04217 & $54.2 / 75.6$ & 14 & 48.1 & 1.75 \\
\hline 6509 & Beta-2-glycoprotein I & P02749 & $38.3 / 8.4$ & 8 & 27.8 & 3.13 \\
\hline 3804 & Contactin-I & Q12860 & $1 \mid 3.3 / 5.6$ & 27 & 35.2 & 0.43 \\
\hline 3716 & Neuronal cell adhesion molecule & Q92823 & |43.9/5.3 & 24 & 23.8 & 0.35 \\
\hline 7408 & Procollagen C-endopeptidase enhancer I & Q15113 & $48.0 / 7.5$ & 11 & 30.5 & 0.65 \\
\hline 3715 & Vitamin D-binding protein & P02774 & $53.0 / 5.2$ & 20 & 45.1 & 0.32 \\
\hline 4710 & Gelsolin & P06396 & $85.7 / 5.7$ & 22 & 23 & 0.09 \\
\hline 3209 & Apolipoprotein A-I & P02647 & $30.8 / 5.4$ & 19 & 61.8 & 0.48 \\
\hline 3407 & Apolipoprotein A-IV & P06727 & $45.4 / 5.2$ & 19 & 55.3 & 2.81 \\
\hline 3805 & Contactin-I & Q12860 & $113.3 / 5.6$ & 31 & 38.1 & 0.39 \\
\hline 1712 & Amyloid-like protein I & P5I693 & $72.2 / 5.4$ & 20 & 34.9 & 0.19 \\
\hline 8215 & Complement component $\mathrm{C} 8$ gamma chain & P07360 & $22.3 / 8.5$ & 5 & 33.2 & 0.73 \\
\hline 5511 & Beta-2-glycoprotein I & P02749 & $38.3 / 8.4$ & 9 & 34.2 & 1.91 \\
\hline 3417 & Haptoglobin & P00738 & $45.2 / 6.1$ & 12 & 27.6 & 2.45 \\
\hline 3314 & Apolipoprotein E & P02649 & $36.1 / 5.5$ & 14 & 46.1 & 0.43 \\
\hline 1713 & $\begin{array}{l}\text { Ectonucleotide pyrophosphatase/phosphodiesterase family } \\
\text { member } 2\end{array}$ & Q13822 & $99.0 / 6.6$ & 21 & 25.7 & 0.34 \\
\hline 4704 & Neural cell adhesion molecule 2 & OI5394 & $93.0 / 5.4$ & 16 & 20.9 & 0.32 \\
\hline 6208 & Metalloproteinase inhibitor 2 & PI6035 & $24.4 / 6.5$ & 6 & 20.9 & 0.55 \\
\hline 8216 & Prostaglandin-H2 D-isomerase & P4I222 & $21.0 / 8.4$ & 4 & 31.1 & 0.30 \\
\hline 3708 & Alpha-IB-glycoprotein & P04217 & $54.2 / 5.6$ & 8 & 20.4 & 0.17 \\
\hline 4706 & Contactin-I & Q12860 & $113.3 / 5.6$ & 19 & 23.8 & 0.56 \\
\hline 4108 & Beta-2-microglobulin form $\mathrm{p} / 5.3$ & P61769 & $13.7 / 5.3$ & 2 & 16.8 & 2.13 \\
\hline 3608 & Hemopexin & P02790 & $51.7 / 6.4$ & 9 & 30.3 & 1.90 \\
\hline 1111 & $\begin{array}{l}\text { Prosaposin; Saposin-A; Saposin-B-Val; Saposin-B; } \\
\text { Saposin-C; Saposin-D fragment }\end{array}$ & P07602 & $58.0 / 5.0$ & 5 & 7.1 & 1.13 \\
\hline 2401 & Clusterin precursor & PI0909 & $52.4 / 5.9$ & 8 & 21.4 & 1.89 \\
\hline 5114 & Acyl-CoA-binding protein & P07। 08 & $10.0 / 6.1$ & 3 & 49.4 & 1.41 \\
\hline 5403 & Neuronal pentraxin-I precursor & Q15818 & $47.1 / 5.8$ & 15 & 30.6 & 2.32 \\
\hline 4309 & Apolipoprotein E & P02649 & $36.1 / 5.5$ & 20 & 60.3 & 0.26 \\
\hline 6206 & Prostaglandin-H2 D-isomerase & P4I 222 & $21.0 / 8.4$ & 4 & 24.7 & 0.22 \\
\hline 4806 & Alpha-2-macroglobulin precursor & P0I023 & $163.3 / 6.0$ & 47 & 37.9 & 0.27 \\
\hline 7405 & Fructose-bisphosphate aldolase C & P09972 & $39.4 / 6.5$ & 14 & 41.2 & 0.68 \\
\hline 1118 & Proprotein convertase I inhibitor & Q9UHG2 & $27.4 / 5.6$ & 6 & 29.6 & 0.35 \\
\hline 8703 & Plasminogen precursor & P00747 & $90.6 / 7.1$ & 21 & 33 & 0.06 \\
\hline 2203 & Prostaglandin-H2 D-isomerase & P4I 222 & $21.0 / 8.4$ & 5 & 24.7 & 1.48 \\
\hline 8402 & Procollagen C-endopeptidase enhancer I & Q15113 & $48.0 / 7.5$ & 15 & 43.9 & 0.26 \\
\hline
\end{tabular}

Note: The spot numbers refer to the marked spots in Figure 3.

Abbreviations: MW, molecular weight; IOD, integrated optical density; CWP, chronic widespread pain; CON, healthy controls; 2-DE, two dimensional gel electrophoresis; $\mathrm{nLC}-\mathrm{MS} / \mathrm{MS}$, nano liquid chromatography tandem mass spectrometry. 
The Journal of Pain Research is an international, peer reviewed, open access, online journal that welcomes laboratory and clinical findings in the fields of pain research and the prevention and management of pain. Original research, reviews, symposium reports, hypothesis formation and commentaries are all considered for publication.
Dovepress

The manuscript management system is completely online and includes a very quick and fair peer-review system, which is all easy to use. Visit http://www.dovepress.com/testimonials.php to read real quotes from published authors. 